ERRATUM

\title{
Early calpain-mediated proteolysis following AMPA receptor activation compromises neuronal survival in cultured hippocampal neurons
}

\author{
Inês M. Araújo, ${ }^{*}$ Maria J. Verdasca, ${ }^{*}$ Ermelindo C. Leal, $†$ Ben A. Bahr, \\ António F. Ambrósio, ${ }^{*} \dagger$ Arsélio P. Carvalho* and Caetana M. Carvalho* \\ *Center for Neuroscience and Cell Biology, Department of Zoology and $\dagger$ Center of Ophthalmology, \\ IBILI, Faculty of Medicine, University of Coimbra, Coimbra, Portugal \\ $\$$ Department of Pharmaceutical Sciences and the Neurosciences Program, Center for Drug Discovery, \\ University of Connecticut, Storrs, Connecticut, USA
}

The authors apologize for an error in Fig. 8(c) of the above manuscript which was published in J. Neurochem. 91, pp1322-1331. In the published manuscript Fig. 8(c) is identical with Fig. 8(a). The correct Fig. 8(c) is now shown below.

Fig. 8 Cellular localization of ${ }_{N}$ SBDPs and time-course of appearance in cultured hippocampal neurons, following non-desensitizing activation of AMPA receptors. The cultures were labeled with antiMAP-2 (red) and with anti- $\mathrm{N}$ SBDP (green), at different time points after exposure to the drugs. Confocal images of control cultures (a), and cultures treated with KA plus CTZ (b) immediately after the exposure (0 min) (c) after $5 \mathrm{~min}$ (d) $15 \mathrm{~min}$ (e) $30 \mathrm{~min}$ (f) $45 \mathrm{~min}$, and (g) after $1 \mathrm{~h}$. Magnification: $600 \mathrm{x}$. (h) Western blot representative of ${ }_{N}$ SBDPs appearance at different time points (upper panel), and quantification of ${ }_{N}$ SBDPs levels (lower panel). The results are presented as arbitrary units of fluorescence (a.u.f) comparing to untreated cultures, using densitometric means \pm SEM of at least three independent experiments. ${ }^{*} p<0.05,{ }^{* *} p<0.01$, significantly different from control; Dunnett's post-test.

\section{Reference}

Araújo I. M., Verdasca M. J., Leal E. C., Bahr B. A., Ambrósio A. F., Carvalho A. P. and Carvalho C. M. (2004) Early calpain-mediated proteolysis following AMPA receptor activation compromises neuronal survival in cultured hippocampal neurons. J. Neurochem. 91, 1322-1331.
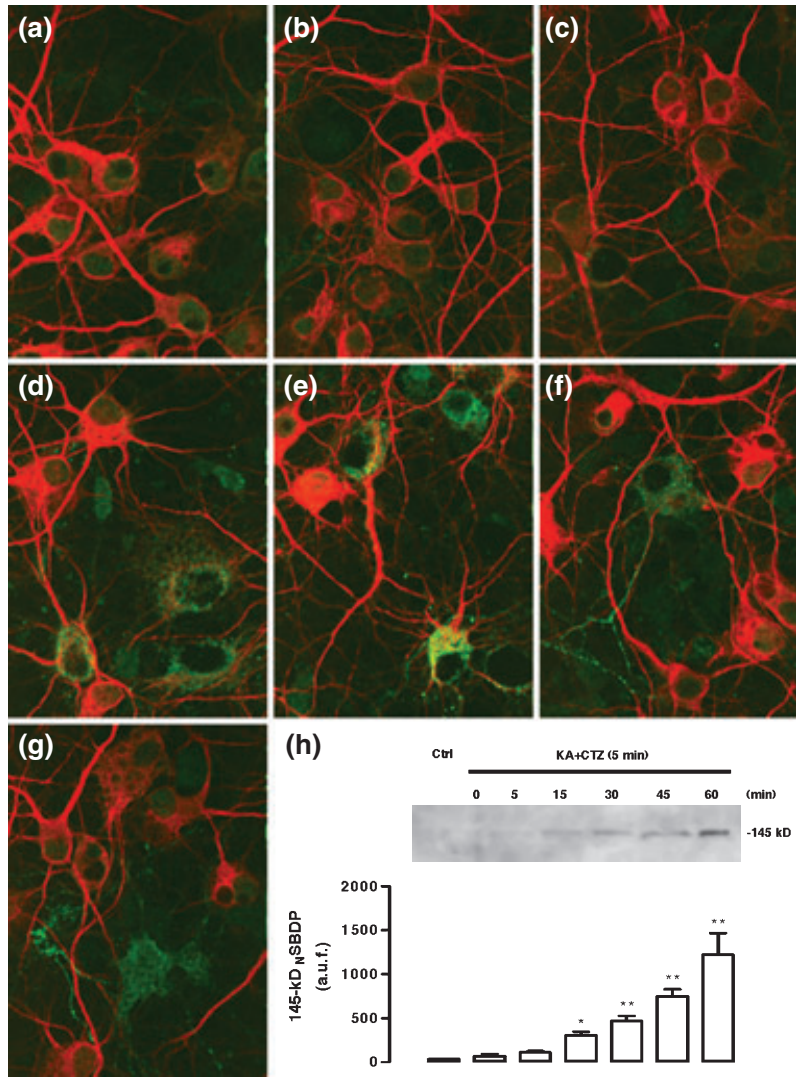